\title{
Correction to: Longitudinal changes in the macula and optic nerve in familial dysautonomia
}

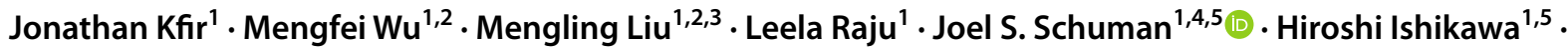 \\ M. Isabel Vanegas ${ }^{6}$. Carlos E. Mendoza-Santiesteban ${ }^{6,7}$. Jose-Alberto Palma ${ }^{6}$. Lucy Norcliffe-Kaufmann ${ }^{6}$. \\ Barr Morgenstein $^{6} \cdot$ Horacio Kaufmann $^{6} \cdot$ Gadi Wollstein $^{1,4,5}$
}

Published online: 2 January 2021

○) Springer-Verlag GmbH Germany, part of Springer Nature 2021

Correction to: Journal of Neurology https://doi.org/10.1007/ s00415-020-10298-4

Unfortunately, the given name of the seventh author was incorrectly tagged in the $\mathrm{xml}$ data, therefore it is abbreviated wrongly as "IM" in Pubmed. The correct given name is MI.

Author name should be M. Isabel Vanegas.

The original article can be found online at https://doi.org/10.1007/ s00415-020-10298-4.

Joel S. Schuman

Joel.Schuman@nyulangone.org

1 Department of Ophthalmology, NYU Langone Health, 222

East 41 St., New York, NY 10017, USA

2 Department of Population Health, NYU Langone Health, New York, NY, USA

3 Department of Environmental Medicine, NYU Langone Health, New York, NY, USA

4 Center for Neural Science, NYU, New York, NY, USA

5 Department of Biomedical Engineering, NYU Tandon School of Engineering, New York, NY, USA

6 Department of Neurology, NYU Langone Health, New York, NY, USA

7 Bascom Palmer Eye Institute, University of Miami, Miami, FL, USA 